\title{
A Century of Insulin
}

\author{
Emily Beckett ${ }^{1,2}$ \\ ${ }^{1}$ Ambulatory Clinical Pharmacist, Broadlawns Medical Center, Des Moines, USA \\ ${ }^{2}$ Broadlawns Family Medicine Residency, Des Moines, USA \\ Email: ukabadi@gmail.com
}

How to cite this paper: Beckett, E. (2021) A Century of Insulin. Journal of Diabetes Mellitus, 11, 185-190.

https://doi.org/10.4236/jdm.2021.115015

Received: September 21, 2021

Accepted: November 12, 2021

Published: November 15, 2021

Copyright (c) 2021 by author(s) and Scientific Research Publishing Inc. This work is licensed under the Creative Commons Attribution International License (CC BY 4.0).

http://creativecommons.org/licenses/by/4.0/

\begin{abstract}
For a century now, the use of insulin has advanced the treatment of diabetes beyond what was ever thought possible in the early 1920s. This article walks through the evolution and ongoing development of progressively more physiologic formulations of insulin. The discovery of insulin was the most important landmark in treatment of diabetes by far. The discovery continues to inspire medical scientists to develop insulins mimicking basal as well as prandial profiles. Similarly, progress has been ongoing in commercial production of insulins from animal sources to advanced recombinant DNA technologies to formulate molecules almost identical to human insulin. Finally, over the years, insulins have become progressively more purified to almost $100 \%$ without contamination leading to almost total elimination of allergic reactions. In conclusion, what was just an idea based on previous knowledge of the role of disorder of pancreatic islets in causing diabetes to discovery of insulin 100 years ago to what is now well established as a life-saving treatment of diabetes.
\end{abstract}

\section{Keywords}

Insulin, Pancreatic Islets, Diabetes, Basal and Prandial Insulins

\section{Pre Insulin Era}

The idea, discovery and manufacture of insulin tops the list of innovative medical research breakthroughs and has revolutionized the management of diabetes. The first description of diabetes can be found in Egyptian medical texts dating back to 552 BC [1] [2]. The name "diabetes" was likely coined by Aretaeus of Cappadocia, a Greek physician (129-199 AD), from the Greek word "siphon" as he noted the association with diabetes and a constant flow of urine [2] [3]. The original treatment proposed a 4-day course of a mixture combining bones, wheat, grain, grit, green lead and earth [4].

Treatment has, of course, evolved today with the discovery of physiologic in- 
sulin and improved prognosis for patients with diabetes. Beyond the original treatment as above, interventions including hyper-caloric diets to counteract urinary loss of calories and Elliott Proctor Joslin's prolonged fasting and "starvation diet" [5] [6] [7] [8] were utilized in the 19th century.

\section{The Idea of Insulin}

It wasn't until 1921 when insulin therapy was discovered, based on the hypothesis that the pancreas secreted a substance that controlled carbohydrate metabolism [5]. The events leading up to the discovery date back to 1884, when Louis Vaillard and Charles Louis Xavier Arnozan discovered pancreatic duct occlusion resulted in pancreatic atrophy without hyperglycemia [9]. Interestingly, the islets of Langerhans were spared from the necrosis of pancreatic atrophy. German physicians Joseph von Mering and Oskar Minkowski attempted to cure diabetes in dogs with pancreatectomy with pancreatic powder extracts [8]. Similar experiments years later replicated these findings, but failed due to toxicity of pancreatic enzymes [10]. There was also difficulty in finding ways to separate the anti-diabetic extract produced by the islet of Langerhans from the rest of the pancreas.

\section{The Discovery of Insulin}

On October 30, 1920, Frederick Banting, an orthopedic surgeon, reviewed an article by Moses Barron, in which four case reports regarding the pancreas were published, relating to the work of Vaillard and Arnozan in 1884. Banting noted that in one case report, a stone blocked the pancreatic duct, leading to atrophy of the exocrine pancreas but preserved the islets of Langerhans-this patient did not develop diabetes [11]. Barron deduced that the islets secreted a hormone controlling glucose metabolism, and Banting became interested in experimenting how to isolate this substance from the islets apart from the rest of the pancreas. His idea included ligating the pancreatic ducts of dogs while keeping them alive until the acini degenerate leaving the isets for isolation of a substance that might relieve glycosuria [12].

Banting approached John James Macleod in November 1920. Macleod was a professor of physiology and department head at the University of Toronto and was agreeable to lend Banting laboratory space to work on his experiments in order to isolate the hormone secreted from the islets of Langerhans. Work began in 1921 after Macleod granted laboratory space to Banting, as well as ten dogs for experiments and a student research assistant Charles Best. [13]

In August 1921, Banting and Best began an experiment involving closure of the pancreatic ducts to degenerate the pancreatic exocrine tissue and to obtain a pancreatic islet from the pure state [4]. This extract, when given four times over four days, resulted in reduced glucose and improved the status of a depancreatized dog [12]. They called this extract "isletin", which was later renamed insulin, resulting now in a century of insulin therapy.

Understanding concerns with previously known impurities in pancreas ex- 
tracts, Macleod invited biochemist James Bertram Collip to assist in purifying isletin for human use. In December 1921, Collip developed a standard insulin-activity assay in rabbits [14] [15] [16] then developed an extraction protocol by using $90 \%$ alcohol, a key improvement that allowed insulin to be soluble, whereas other impurities precipitated [17]. In January 1922, Collip's isolate was injected into a 14-year-old patient with diabetes, Leonard Thompson. Injection of this extract resulted in normalization of glycemia, glycosuria and ketonuria [4].

\section{Manufacturing Insulin}

By summer of 1922, Banting began treating patients with diabetes in a private clinic in Toronto [18]. The first US patent application for insulin was filed under the names Collip and Best in June 1922 [19]. In the autumn of 1922, Eli Lilly began manufacturing insulin from animal pancreas, but couldn't meet demand and potency varied up to $25 \%$ per lot. George Walden, a scientist at Eli Lilly, developed a method involving isoelectric precipitation of insulin to improve both purity and yield of insulin [20].

In late 1922, Danish Nobel Prize winner August Krogh from the University of Copenhagen met with Banting and Macleod and received authorization from the University of Toronto to produce insulin in Denmark at the Nordisk Insulin Laboratory, which he founded and later became Novo Nordisk [20]. Soon, Hoechst pharmaceuticals in Germany joined the race in manufacturing insulin. Also noteworthy, Krogh wrote nomination letters for Banting and Macleod after meeting with the investigators; in 1923, Banting and Macleod were awarded the Nobel Prize in Physiology and Medicine [21].

\section{Attuning Insulin}

To this point, Banting and Best's insulin preparation lasted about 6 hours, requiring several injections daily and resulted inevitably in peaks of hyperglycemia throughout the day. Efforts to prolong its action and reduce variability commenced in the years after insulin's official discovery. In 1936, Hans Christian Hagedorn, a chemist from Denmark, produced a longer acting insulin by adding protamine, a basic protein. In Toronto in 1939, David Alymen Scott and Fisher prolonged insulin's action even further by adding zinc, creating the insulin-protamine zinc complex, whose duration lasted 24 - 36 hours [22]. In 1946, isophane neutral protamine Hagedorn was manufactured and found it could be mixed with regular insulin. In 1951-52, the amorphous "lente" insulins (semilente, lente and ultralente) were developed and found that the pharmacokinetics and hypoglycemic effects depended on the proportion of zinc. Semilente, Lente and Ultralente insulins matched the profiles of regular crystalline, NPH and Protamine Zinc insulins respectively.

\section{Modern Insulin}

Through this time, improvements in insulin purification techniques were being 
trialed, with human insulin being produced using recombinant DNA technology based on genetic modifications of bacteria in the 1970s. It wasn't until 1978 that the first recombinant DNA was prepared using the combination of insulin A and B chains expressed from E. coli bacteria. Thereafter, Genentech and Lilly signed an agreement to commercialize recombinant DNA insulin [4]. In 1982, with the advent of synthetic insulins which created fewer allergenic concerns in patients compared to animal insulin, Humulin $\mathrm{R}$ and Humulin $\mathrm{N}$ were marketed en masse by Eli Lilly [4]. During the 1980-90s, analog insulins using genetically modified insulins resulting from alterations in amino acid sequences were developed. In 1996, Eli Lilly produced the first short-acting insulin lispro under the brand Humalog, which was followed by the manufacture of insulin aspart (Novolog) in 2000 by Novo Nordisk and insulin glulisine (Apidra) in 2004 by Sanofi [4]. In recent years, several bioavailable faster acting insulins have been approved.

Basal insulins were also developed around this time. Insulin glargine, manufactured by Hoechst then (presently Sanofi) and approved for use in 2000 forms micro precipitate at the site of injection; this along with alterations in amino acid sequence results in prolonged absorption with minimal peaks [23] [24]. Insulin detemir, produced by Novo Nordisk and approved in 2005 binds readily to circulating albumin and demonstrates a prolonged duration of action due to gradual release from the bound product as well as structural amino acid changes [25]. Since the early 2000s, additional basal insulins, including another glargine (Basaglar), 3 times concentrated insulin glargine (Toujeo), insulin degludec (Tresiba) have been approved. Most recently, interchangeable biosimilar glargine (Semglee) was approved by FDA and is marketed in USA as well as a few other countries. The presently available basal insulins are injected daily. New insulin formulations with once weekly administration are being studied.

Understandably, discovering needle-free insulin would be a breakthrough in itself. The concept of breath-administered insulin was documented initially in 1925; a relaunch occurred in 1971. In 2006, Pfizer and Sanofi-Aventis developed Exubera, the first marketed inhaled insulin [26] [27] [28]. This dry powder insulin is formulated with appropriate particulate characteristics for deposition in the alveoli. While inhaled insulin has low bioavailability (about $9 \%$ of the amount inhaled), it ultimately results in adequate serum insulin levels. Critics of its use noted a bulky inhaler device and lack of additional benefit over fast-acting analogs. In 2007, Pfizer ceased sales of Exubera due to lack of acceptance from providers and patients [4]. In 2014, Afreeza inhaled insulin also absorbed by alveoli was approved, however it is not commonly used. Finally, ongoing studies assessing transdermal insulin patch as well as oral insulin formulations are underway.

\section{Summary}

While Banting was involved in the discovery of insulin a century ago, he ultimately dreamt of transplanting a pancreas into humans [29]. Looking ahead, cur- 
rent work with artificial pancreases, creating a closed-loop system controlling blood sugar may be the future of diabetes. The advent of insulin pumps and the potential of weekly insulin injections are also advanced in achieving glucose control. The discovery of insulin one hundred years ago created a milestone in medicine and provides hope for diabetes cure in the future.

\section{Conflicts of Interest}

The author declares no conflicts of interest regarding the publication of this paper.

\section{References}

[1] Oubre, A.Y., Carlson, T.J., King, S.R. and Reaven, G.M. (1997) From Plant to Patient: An Ethnomedical Approach to the Identification of New Drugs for the Treatment of NIDDM. Diabetologia, 40, 614-617. https://doi.org/10.1007/s001250050724

[2] Marwood, S. (1973) Diabetes Mellitus Some Reflections. The Journal of the Royal College of General Practitioners, 23, 38-45.

[3] Gemmill, C.L. (1972) The Greek Concept of Diabetes. Bulletin of the New York Academy of Medicine, 48, 1033-1036.

[4] Vecchio, I., Tornali, C., Bragazzi, N.L. and Martini, M. (2018) The Discovery of Insulin: An Important Milestone in the History of Medicine. Frontiers in Endocrinology, 9, 613. https://doi.org/10.3389/fendo.2018.00613

[5] Bliss, M. (1982) The Discovery of Insulin. University of Chicago Press, Chicago. https://doi.org/10.1007/978-1-349-09612-1_9

[6] Mazur, A. (2011) Why Were "Starvation Diets" Promoted for Diabetes in the Proinsulin Period? Nutrition Journal, 10, 23. https://doi.org/10.1186/1475-2891-10-23

[7] Joslin, E.P. (1916) The Treatment of Diabetes Mellitus: With Observations upon the Disease Based upon One Thousand Cases. Lea \& Febiger, Philadelphia. https://doi.org/10.1097/00000441-191710000-00015

[8] Joslin, E.P., Root, H.F., White, P., Marble, A. and Bailey, C.C. (1947) The Treatment of Diabetes Mellitus. 8th Edition, Henry Kimpton, London.

[9] Colwell, A.R. (1968) Fifty Years of Diabetes in Perspective. Diabetes, 17, 599-610. https://doi.org/10.2337/diab.17.10.599

[10] Levene, P.A. (1894) Studies in Phloridzin Glycosuria. The Journal of Physiology, 17, 259-271. https://doi.org/10.1113/jphysiol.1894.sp000529

[11] Barron, M. (1920) The Relation of the Islets of Langerhans to Diabetes with Special Reference to Cases of Pancreatic Lithiasis. Surgery, Gynecology and Obstetrics, 31, 437-448.

[12] Hegele, R. and Maltman, G. (2020) Insulin's Centenary: The Birth of an Idea. The Lancet Diabetes \& Endocrinology, 8, 971-977. https://doi.org/10.1016/S2213-8587(20)30337-5

[13] Quianzon, C. and Cheikh, L. (2012) History of Insulin. Journal of Community Hospital Internal Medicine Perspectives, 2, Article No. 18701. https://doi.org/10.3402/jchimp.v2i2.18701

[14] Bliss, M. (1982) Banting's, Best's, and Collip's Accounts of the Discovery of Insulin. Bulletin of the History of Medicine, 56, 554-568.

[15] Banting, F.G. (1940) The Story of Insulin: Unpublished Memoir 1939-40. Fisher Li- 
brary of Rare Books, University of Toronto, Toronto.

[16] Macleod, J.J. (1978) History of the Researches Leading to the Discovery of Insulin: With an Introduction by Lloyd G Stevenson. Bulletin of the History of Medicine, 52, 295-312.

[17] Collip, J.B. (1923) The Original Method as Used for the Isolation of Insulin in Semipure form for the Treatment of the First Clinical Cases. Journal of Biological Chemistry, 55, 40-41.

[18] de Leiva-Hidalgo, A. and de Leiva-Pérez, A. (2020) Experiences of First Insulin Treated Patients (1922-23). American Journal of Therapeutics, 27, e13-e23. https://doi.org/10.1097/MJT.0000000000001069

[19] Hegele, R.A. (2017) Insulin Affordability. The Lancet Diabetes \& Endocrinology, 5, 324. https://doi.org/10.1016/S2213-8587(17)30115-8

[20] Rosenfeld, L. (2002) Insulin: Discovery and Controversy. Clinical Chemistry, 48, 2270-2288. https://doi.org/10.1093/clinchem/48.12.2270

[21] Lindsten, J. (2001, April 2) August Krogh and the Nobel Prize to Banting and Macleod.

https://www.nobelprize.org/prizes/themes/august-krogh-and-the-nobel-prize-to-ba nting-and-macleod/\#: :text=The\%20Nobel\%20Prize\%20in\%20Physiology\%20or\%2 0Medicine\%20in\%201923\%20for,was\%20divided\%20between\%20Frederick\%20G.\& text=They\%20published\%20their\%20work\%20on,Krogh\%3B\%20and\%20Macleod\% 20by\%20G.\%20N.

[22] Bliss, M. (1993) The History of Insulin. Diabetes Care, 16, 4-7. https://doi.org/10.2337/diacare.16.3.4

[23] Hirsch, I. (2005) Insulin Analogues. The New England Journal of Medicine, 352, 174-183. https://doi.org/10.1056/NEJMra040832

[24] Lantus Prescribing Information (Internet). Sanofi-Aventis US LLC, Bridewater. http://products.sanofi.us/lantus/lantus.html

[25] Levemir Prescribing Information (Internet). Novo Nordisk, Princeton. http://www.novo-pi.com/levemir.pdf

[26] Macleod, J.J.R. (1926) Carbohydrate Metabolism and Insulin. Vol. 1. Longmans, Green and Co., London.

[27] Noble, E.C. (1971) Who Discovered Insulin? Guy’s Hospital Gazette, 85, 452-453.

[28] de Leiva-Hidalgo, A., Bruguès-Bruguès, E. and de Leiva-Péreza, A. (2011) From Pancreatic Extracts to Artificial Pancreas: History, Science and Controversies about the Discovery of the Pancreatic Antidiabetic Hormone. Avances en Diabetología, 27, 27-38. https://doi.org/10.1016/S1134-3230(11)70005-9

[29] Dean, P.G., Kukla, A., Stegall, M.D. and Kudva, Y.C. (2017) Pancreas Transplantation. BMJ, 357, j1321. https://doi.org/10.1136/bmj.j1321 